\title{
GENDER DIFFERENCES DOMINATE SLEEP DISORDER PATIENTS' BODY PROBLEM COMPLAINTS
}

\author{
TED L. ROSENTHAL*, ELAINE S. BRYANT*, HELIO LEMMI*,**
}

\begin{abstract}
SUMMARY - We studied it age, gender, diagnostic status, and psychiatric features affected 291 consecutive sleep disorder patient's body complaints on a brief checklist. Gender had a strong impact on all four (tested) dependent measures, with women reporting more distress than men. Age produced significant regressions on two measures, with younger patients complaining more than older. Presence of psychiatric features was associated with more complaints on one dependent measure - previously found to reflect internal medicine patients' emotional distress. The results of regression analyses were largely supported by follow-up ANOVAs. However, contrasting insomniac versus hypersomniac versus all other sleep disorder diagnoses did not affect body complaints on any dependent measure. The results caution against combining males and females to compare self-reported distress between sleep disorders.
\end{abstract}

KEY WORDS: complaint patterns, gender differences, body problems, nonspecific complaints.

\section{Diferenças por gênero prevalecem na distribuição de queixas somáticas de pacientes com distúrbios do sono}

RESUMO - Investigamos o efeito da idade, sexo, estado clínico e psiquiátrico de 291 pacientes com distúrbios do sono em relação a queixas identificadas por breve questionário de sintomas somáticos. Em relação ao sexo, diferenças significativas foram evidenciadas para os quatro grupos da lista de queixas (Tabela 1): inespecíficos (itens 2, 5, 6, 7 e 12), específicos (itens 1, 3, 4, 8, 910 e 11), total (itens 1 a 12) e total geral (total + itens 13, 14 e 15). Mulheres referiram mais sintomas que os homens. A idade mostrou impacto nos grupos inespecífico e total. Pacientes moços queixaram-se mais que idosos. Pacientes com sintomas psiquiátricos identificaram-se principalmente com o grupo inespecífico. Os resultados da análise regressiva foram evidenciados pela análise ANOVA. Ao se comparar insônia vs hipersônia vs outros problemas do sono juntos, não se demonstrou relação evidente com qualquer dos grupos de queixas somáticas. Os resultados alertam para os problemas potenciais que podem resultar quando os dois sexos são agrupados com o propósito de identificação do tipo de distúrbios do sono por meio de questionários auto-administrados.

PALAVRAS-CHAVE: padrão de distribuição de queixas, diferenças por gênero (sexo), problemas somáticos, queixas inespecíficas.

Based on an epidemiological study of which outpatient complaints were most often or rarely associated with psychiatric diagnoses ${ }^{1}$, we developed a checklist of body complaints that did (Nonspecific) or did not (Specific) predict emotional distress. In a first version, the checklist required multiple patient answers for each body symptom. We found that complaint scores correlated with internists' ratings of degree of emotional involvement in first visit office cases, and also with known anxiety and depression scales ${ }^{3}$. We then simplified the checklist format to require just one answer

* College of Medicine University of Tennessee, Memphis and **Neurosciences and Sleep Disorders Center, Baptist Memorial Hospital. Memphis TN, USA. Aceite: 10-maio-1994. 
per symptom. The short version proved useful to differentiate psychiatric patients with mood versus anxiety disorders ${ }^{2}$. From those results we felt it of interest to study the body complaints reported by sleep disorder patients, using the brief answer format. A main concern was whether Insomniac versus Hypersomniac versus remaining sleep cases differed in the type and severity of bodily complaints.

\section{METHODS}

We studied 291 consecutive patients, referred for evaluation, who skipped no more than two body problems items and who completed subsequent polysomnography at the Sleep Disorders Center of Baptist Memorial Hospital. Fewer than ten other cases were excluded due to missing data. There were 102 women and 189 men with an age range from 16 to 87 years (Mean=45.88 years, $S D=13.45)$. From their sleep laboratory findings, patients were divided into three diagnostic groups based on the 1990 International Classification of Sleep Disorders ${ }^{5}$ : there were 96 Insomniacs (42 women, 54 men), 143 Hypersomniacs (38 women, 105 men), and 52 cases (22 women, 30 men) combining all other diagnoses as a Residual group. Also, 79 patients (41 women, 38 men) were given a code for psychiatric symptoms-virtually always anxiety or depression. These attributes of gender, age, diagnostic group, and presence versus absence of psychiatric features were the independent variables for regression analyses.

Body Problem Checklist (BPC). The BPC was given before sleep testing, and kept apart from diagnosticians who were "blind" to patients' answers. The 15 BPC items, listed in Table 1, were each rated for complaints (i.e., "pain or discomfort or worry") on a 4-point Likert scale from Not At All=0 to Very Much=3 distress. Items were added into four complaint scores as follows:

Nonspecific complaints comprised the items (numbers 2, 5, 6, 7, and 12 in Table 1) reflecting abdominal pain, dizziness, nervousness, headaches, and fatigue. Each complaint was previously found to forecast a psychiatric diagnosis in $40 \%$ of patients or more ${ }^{1}$, and the sum of nonspecific complaints proved to be a very good predictor of emotional distress as judged by internists, and on other measures ${ }^{3}$.

Specific complaints spanned the prior items (numbers 1, 3, 4, 8, 9, 10 and 11 in Table 1) that were less related to psychiatric problems, and we retained the sum of items 1 through 12 , previously taken as a Total score ${ }^{2,3}$.

Finally, three new items (numbers 13, 14, and 15 in Table 1) were included which, when combined with the other complaints by summing across all 15 items, yielded a Grand Total complaint score. Thus, the BPC sums of Nonspecific, Specific, (former) Total, and (new) Grand Total complaint scores were the dependent variables.

Statistical analysis. The main analyses were stepwise linear multiple regressions for each dependent complaint measure, with the $p=0.05$ level required for retention. When an independent variable was retained, we explored it further by means of single-classification ANOVA. For that purpose, the continuous age variable was divided into for levels as follows: age up to 30 years (group $n=35$ cases); 30-45 years $(n=122) ; 45-60$ years $(n=91)$; and over 60 years $(n=43)$. These chosen age levels gave very similar gender proportions with all differences per level below $4.4 \%$.

\section{RESULTS}

The percentages of complaint responses (from nil to very much) on each item are listed for women, for men, and for the sexes. combined, in Table 1, which makes evident that women felt freer than men to express complaints on the BPC.

The regression analyses are summarized in Table 2, which shows that gender was the strongest covariate of complaints on all the dependent measures. Likewise, all the ANOVAs for gender were highly significant, with the smallest $F(1,289)=35.05 p<0.0001$, on the Specific complaint scores. The gender means (SDs in parentheses) were as follows: on Grand Total, women=19.23 (6.92), men=12.53 (7.21); on Total, women=15.81 (5.51), men=10.73 (5.95); on Nonspecific, women=7.64 (3.07), $m e n=5.10$ (3.22); and on Specific complaints, women=8.18 (3.53), $\operatorname{men}=5.63(3.49)$.

Age level played significant roles in the regressions for the Total and Nonspecific complaints, but a significant ANOVA only emerged on the Nonspecific scores, $F(3,287)=4,28, p<0.01$. It came about because the youngest age level complained the most and the two eldest groups were the most stoic. This is shown by the pattern of Means (SDs in parentheses) from voungest to oldest as follows: 7.46 (3.40); 6.28 (3.39); 5.29 (3.25); 


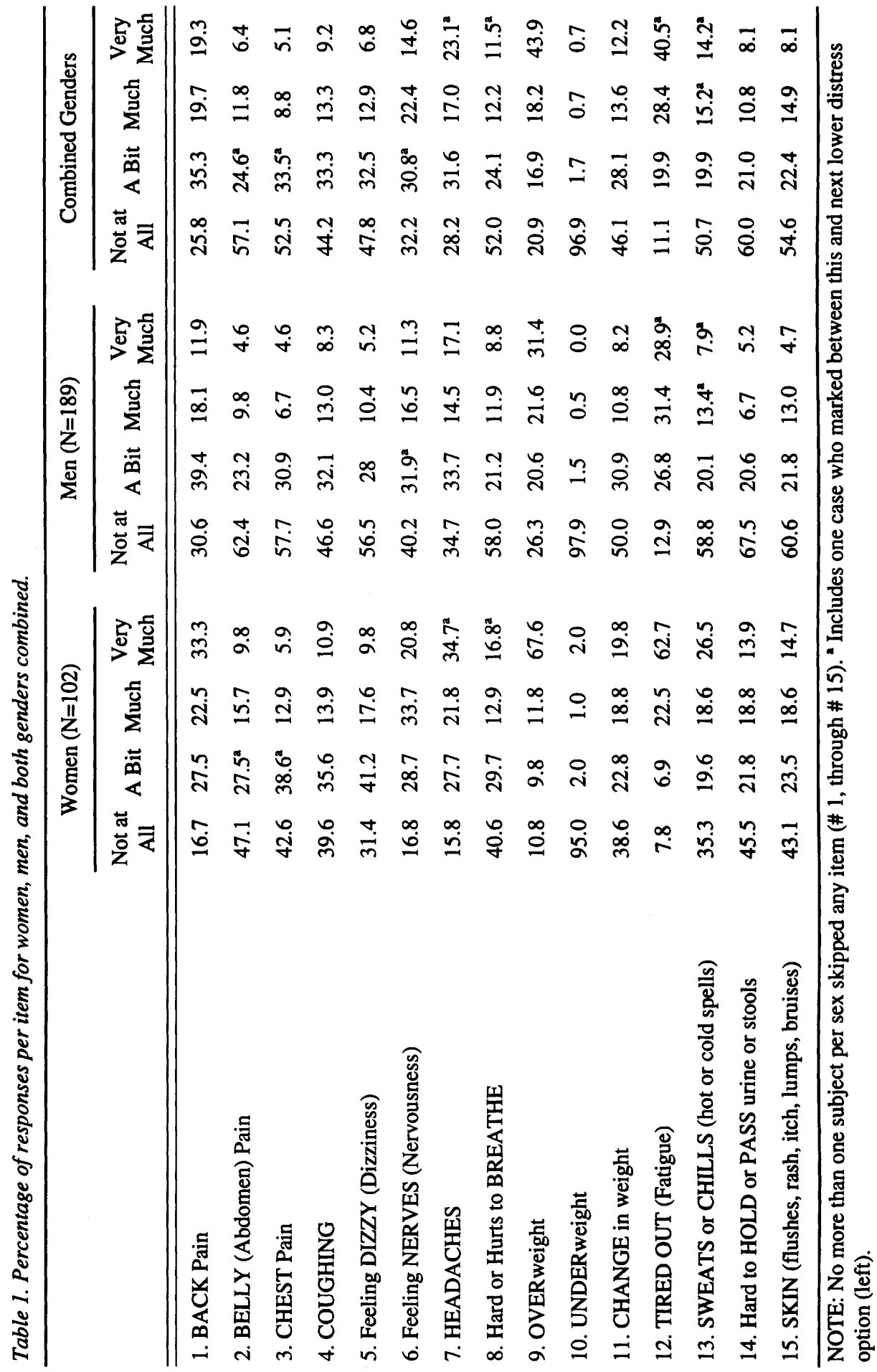


Table 2. Summary of significant stepwise multiple regression results on the dependent complaint measures.

\begin{tabular}{|c|c|c|c|c|}
\hline Independent variables & Partial $\mathbf{R}^{\mathbf{2}}$ & Model R2 & $\mathrm{F}$ & $\mathbf{p}$ \\
\hline & \multicolumn{4}{|c|}{ Grand Total complaints (items $1-15)^{*}$} \\
\hline \multirow[t]{2}{*}{ Gender } & {$[0.1691]$} & {$[0.1691]$} & [58.81] & {$[0.0001]$} \\
\hline & \multicolumn{4}{|c|}{ Total complaints (items $1-12)^{*}$} \\
\hline Gender & {$[0.1498]$} & {$[0.1498]$} & [50.93] & {$[0.0001]$} \\
\hline \multirow[t]{2}{*}{ Age } & {$[0.0149]$} & {$[0.1647]$} & {$[5.12]$} & [0.0243] \\
\hline & \multicolumn{4}{|c|}{ Nonspecific complaints (items $2,5,6,7$ and 12 )* } \\
\hline Gender & [0.1283] & {$[0.1283]$} & [42.52] & {$[0.0001]$} \\
\hline Age & {$[0.0391]$} & {$[0.1673]$} & [13.51] & {$[0.0003]$} \\
\hline \multirow[t]{2}{*}{ Psychiatric (yes or no) } & {$[0.0114]$} & {$[0.1787]$} & {$[3.97]$} & {$[0.0472]$} \\
\hline & \multicolumn{4}{|c|}{ Specific complaints (items $1,3,4,8,9,10$ and 11 )* } \\
\hline Gender & {$[0.1082]$} & {$[0.1082]$} & [35.05] & {$[0.0001]$} \\
\hline
\end{tabular}

Note: *, outcome measures.

and 5.47 (3.26). Thus, pairwise comparisons with Fisher LSD tests showed that the patients aged 45-60 complained significantly less than both younger levels, and that the oldest complained less than the youngest level (all ps<0.05), despite any geriatric infirmities.

As expected, patients judged to show psychiatric symptoms gave more Nonspecific complaints as found in the regression data and also by ANOVA, $F(1,289)=9.45, p<0.003$. The Nonspecific complaint means (and SDs) were: with psychiatric signs $=6.97$ (3.38); and without signs $=5.62$ (3.32). In contrast to all forementioned results, the diagnostic (Insomnias, Hypersomnias, or Residual) group variable was not accepted in any regression analysis. Moreover, when we also compared diagnostic groups by ANOVAs, no differences were suggested on any complaint measure, largest $F(2,288)=1.49$, NS.

\section{COMMENTS}

The sleep disorder groups failed to differ, perhaps because the three categories were too broad. Future research that compares groups based on finer distinctions among specific sleep disorders might still yield complaint differences. It was expected that women's complaints would exceed men's, but the degree was striking. Gender proved far stronger than all other grouping variables. We previously found rather similar results with another checklist - the Cornell Medical Index Health Questionnaire - and a very different population, comparing irritable bowel versus Crohn's disease versus acute illness in gastroenterology patients ${ }^{4}$.

Such strong gender effects on complaints suggest that it is clearly risky to combine the sexes in research using reports of symptom severity as døpendent measures. For instances, Table 1 illustrates how very different impressions can be created when men's and women's responses are given separately, or are only shown in combined form. Thus, future research to compare specific sleep disorder groups, alternative treatments, or patients satisfaction should beware of combining females' with males' complaint reports. Either each gender should be studied separately, or else their numbers kept equal or closely proportional. Otherwise, complaint differences that actually stem from gender may be falsely attributed to other variables. 
Acknowledgments - We thank Sharon Burt, R. PSG., for giving the inventories and Paula Gray for manuscript typing.

\section{REFERENCES}

1. Brain ST, Spaulding WB. The importance of coding presenting symptoms. Can Med Assn J 1967, 97 : 953-959.

2. Rosenthal TL, Downs JM, Arheart KL, Deal N, Downs AFD, Rosenthal RH. Similarities and differences on five inventories among mood and anxiety disorder patients. Behav Res The 1991, 29: 239-247.

3. Rosenthal TL, Miller ST, Rosenthal RH, Shadish WR, Fogleman BS, Dismuke SM. Assessing emotional distress at the internist's office. Behav Res The 1991, 29: 249-252.

4. Rosenthal TL, Wruble LD, Rosenthal RH, Edwards NB. Complaint patterns of patients with irritable bowel syndrome, Crohn's disease and acute gastroenterological illness. Behav Res The 1987, 25: 99-112.

5. The International Classification of Sleep Disorders. Diagnostic and Coding Manual. Rochester MN: American Sleep Disorders Assn, 1990. 